\title{
Consecutive Bestatin-Hormone Regimen Induces Redifferentiation of Cancer Cells in Vitro
}

\author{
Shinichi Okuyama and Hitoshi Mishina \\ Department of Radiology, Tohoku Rosai Hospital, Sendai \\ 980
}

Onuyama, S. and Mishina, H. Consecutive Bestatin-Hormone Regimen Induces Redifferentiation of Cancer Cells in Vitro. Tohoku J. exp. Med., 1984, 143 (4), 501-502 — When undifferentiated murine mammary adenocarcinoma cells were consecutively exposed to bestatin and estradiol or testosterone in vitro, morphological signs of redifferentiation of the cells were observed along with cellular enlargement and subsequent cell loss. These observations suggest that similar treatments can be applied clinically to cancers of the breast and prostate. - redifferentiation therapy; experimental carcinoma; bestatin; sex hor-

mones

Bestatin reduces the saturation density of cultured FM3A cells, undifferentiated mammary adenocarcinoma cells of the mouse, suggesting cell redifferentiation (Okuyama and Mishina 1983a,b). The present paper reports that redifferentiation was actually induced by treatment with this drug followed by estradiol or testosterone.

Details of the cell culture techniques have already been described in a previous paper (Okuyama and Mishina 1983b).

Bestatin induced somal and nuclear enlargement of the cells. On day-3 of the exposure to bestatin $(300 \mu \mathrm{g} / \mathrm{ml})$, a dose of marginal cell killing of estradiol benzoate $(75 \mathrm{U} / \mathrm{ml})$ was added to the culture medium, which induced cell redifferentiation (Fig. 1). Judgement of cellular redifferentiation was performed according to Awano and Matsuzawa (1977). Reductions in viable cell count were also seen after estradiol was administered singly or in combination with bestatin (Fig. 2). Testosterone propionate in a dose of marginal cell killing induced the cell redifferentiation only when it was used in combination with bestatin. A certain fraction of the cancer cells thus treated could have acquired definitely limited length of life via redifferentation, and died off because kinetic data indicated that the incidence of redifferentiation increases as the dose of bestatin increases while estradiol plays a trigger function (unpublished). These observations may imply that a consecutive bestatin-hormone regimen would be a new category of cancer therapy in such endocrine malignancies as cancer of the breast or prostate.

\section{References}

1) Awano, T. \& Matsuzawa, T. (1977) Accumulation and biological effects of gallium in malignant cell lines in vitro. Kakuigaku, 14, 73-81. (in Japanese with English summary)

Received for publication, February 6, 1984.

Request reprints to: S. Okuyama, M.D., Tohoku Rosai Hospital, Sendai 980, Japan. 


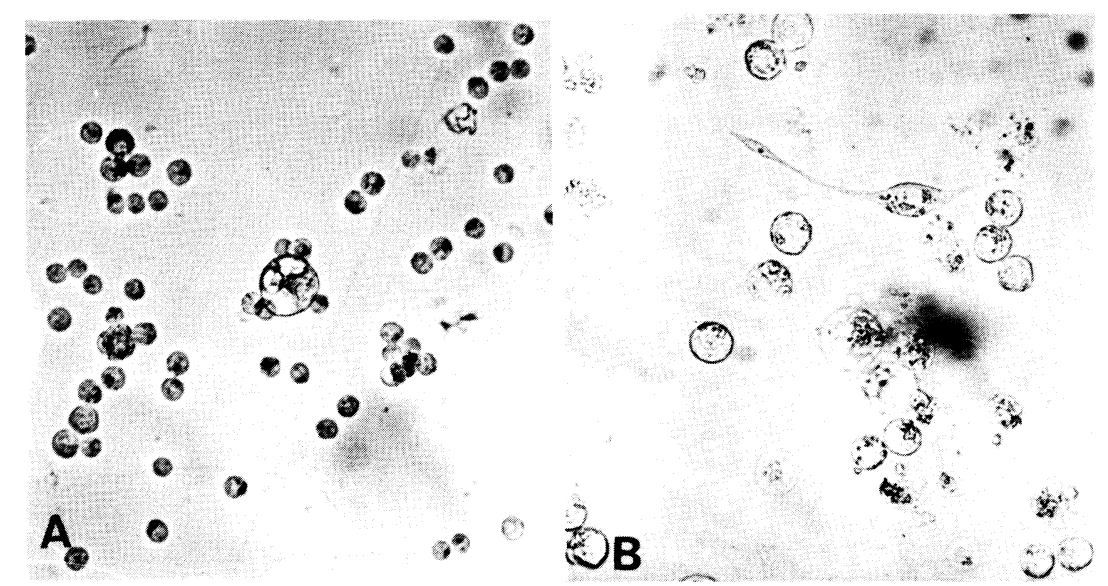

Fig. 1. The consecutive bestatin-hormone (estradiol or testosterone) treatment induced somal and nuclear enlargement in FM3A undifferentiated mammary adenocarcinoma cells of the mouse in vitro. It induced cellular redifferentiation, too. $A$ : Control. $B$ : Bestatin-estradiol.

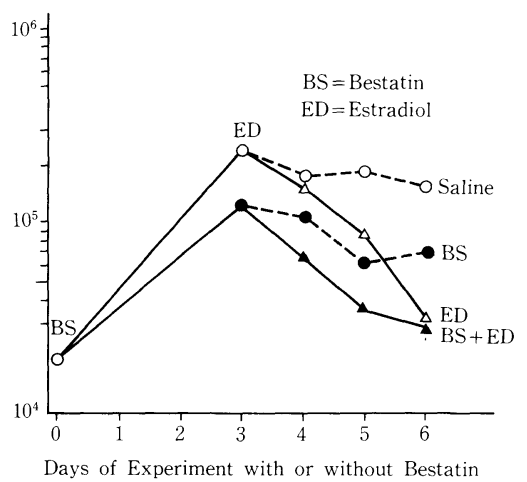

Fig. 2. The consecutive bestatin-hormone treatment additively reduced viable cell count of FM3A cells in vitro.

2) Okuyama, S. \& Mishina, H. (1983a) Consecutive bestatin-hormone regimen for cancer redifferentiation. In : Proc. 13th Int. Congr. Chemother., Vienna, 28 Aug.-2 Sep., Part 289, pp. 11-14.

3) Okuyama, S. \& Mishina, H. (1983b) Decrease in saturation density of mammalian carcinoma cell culture during exposure to bestatin, a clinically applicable agent. Tohoku J.exp. Med., 142, 349-350. 